\title{
Injection Parameter Optimization of Water Wells in Low Permeability Reservoirs
}

\author{
Bo Luo ${ }^{1}$, Jianchun Guo ${ }^{1, *}$, Cong Lu ${ }^{1,2}$, Haiyan Zhu ${ }^{1}$, Zhihong Zhao ${ }^{1}$, \\ Chen $\mathrm{Li}^{3}$, Yulong Zhou ${ }^{3}$ \\ ${ }^{1}$ State Key Laboratory of Oil and Gas Reservoir Geology and Exploitation, \\ Southwest Petroleum University, Chengdu 610500, China \\ ${ }^{2}$ Institute of Petroleum Engineering, Clausthal University of Technology, \\ Agricola Str. 10, 38678 Clausthal-Zellerfeld, Germany \\ ${ }^{3}$ Luming Oil\&Gas Exploration and Development Co.Ltd., of Sinopec Shengli \\ Oilfield Company, Dongying 257000, China \\ ${ }^{*}$ Corresponding Author: Jianchun Guo
}

\begin{abstract}
Low permeability reservoirs are characterized by poor porosity, low permeability, complicated pore structure and productions, high exploitation difficulty, high costs and insufficient natural energy. Water injection as a means of enhancing recovery has been practiced worldwide for many years in the oil industry. In order to enhance the recovery of those low porosity and ultra-low permeability reservoir, advanced water injection and synchronous water injection, and other water injection methods were applied to replenish reservoir energy. In this paper, a five spot well pattern was built to optimize the appropriate injection parameters for Z23 low permeability reservoir in Shengli Oilfield. The range of injection time and injection rate were pre-established, and then the influence of injection parameter on block oil saturation, block oil recovery, total oil production, water cut and block water breakthrough time were analysed. Simulation results showed that the optimal injection time was advanced water injection 3 months and injection rate was 14m3/day in Z23. This paper provided an effective theoretical support to the development of Z23 low permeability reservoir. Meanwhile, the research method of this paper could serve as an important part in the development of this kind of low permeability reservoirs.
\end{abstract}

Keywords: injection parameter, low permeability reservoir, water well, numerical simulation

\section{Introduction}

As the formation fluid extraction, formation energy will gradually decrease. This will lead to the drop of effective overburden pressure, the deformation of rock, and the decline of porosity and permeability. Water injection is a key technology applied to maintain the reservoir pressure, sustain the oil production and maximize oil recovery [1-2]. In the case of low permeability reservoirs, it is possible to create large fractures, the size and orientation of which can have a profound effect on sweep patterns, producer placement, and reservoir management. Z23 of Shengli oilfield is low-porosity and ultra-low permeability reservoirs. Water injection was selected as an efficient method to improve the reservoir pressure and oil recovery. Numerical simulation is need to figure out the proper injection parameters for Z23, In this paper, a five spot well pattern was applied to model the production performance of Z23. The influence of injection parameters on Z23 production performance analyzed. The simulation results

${ }^{*}$ Corresponding Author 
provided an effective theoretical support to the development of Z23 low permeability reservoir.

In this paper, Section 2 describes the water injection development in low permeability reservoirs. Section 3 gave the methodology to optimize the injection parameters of water well. Section 4 presented a result analysis and discussion. Conclusions are summarized in Section 5.

\section{Literature Review}

Water injection is a key technology applied to pressure maintenance and improved oil recovery (IOR). The effectiveness of water injection in IOR is the success factor in maximizing oil recovery because it keeps the reservoir pressure which acts as the energy to sustain the oil flowing from reservoir [3-4]. So, most oil field companies applied the combination of injection-production well pattern to improve the oil production rate and recovery.

Understanding the reservoir fluid dynamics including the injected water movement is the key for the optimization the water injection. Several laboratory studies demonstrated the potential of water injection to improve oil recovery in sandstone rock. Most core-flood experiments showed increases in oil recovery in both secondary mode as well as tertiary mode. Several mechanisms were proposed to explain how oil recovery can be improve by water injection [5-7]. Some scholars suggested that the improved sweep efficiency, caused by fines migration and clay swelling as result of fresh water injection, is the main mechanism of improved oil recovery. And some scholars attributed to oil recovery increase to multi-component ionic exchange between the rock minerals and injection brine, which reduces the ion binding between the crude oil and rock surface. In addition, some scholars attributed to oil recovery increase to wettability alteration [8].

Water injection as a means of enhancing recovery has been practiced worldwide for many years in the oil industry [9-12]. Oilfield practice proves that the water injection development can complement formation energy to a certain extent. Injection water can prevent the decline of reservoir physical property caused by formation pressure drop, enhance the water sweep efficiency, and improve the well production performance. All of those improvement can finally contribute to a comprehensive benefits for oilfield.

Hydraulic fracturing is an important technical measure for oil well production and water well injection in low permeability reservoir [13-15]. From the point of improving reservoir pressure and water injection volume, it is necessary to implement water well fracturing in low permeability reservoir. But the fracturing of water well may cause premature water breakout and reduce the production efficiency. So research on whether the water well should fracture and the injection parameter optimization is critical [1618]. The water injection is designed by considering the injection pattern, the injection rates and the injection pressure as well as the operation accessibility and water quality requirement.

The fracture length and fracture width and fracture conductivity of water injection wells have a significant role on oil production. The numerical simulation method of oil and water wells fracturing is need [19-20]. Different low permeability reservoir needs different injection parameters which are fit for its characteristics. In this paper, the injection parameters of Z23 in Shengli Oilfield will be discussed. 


\section{Methodology}

\subsection{Field Introduction}

Z23 belongs to low-porosity and ultra-low permeability reservoirs with average porosity of $14.12 \%$ and average permeability $1 \mathrm{mD}$. The depth of target formation is about $3600 \mathrm{~m}$. In this paper, a five spot well pattern was applied to model the production performance of Z23. The influence of injection parameters on Z23 production performance analyzed. The simulation results provided an effective theoretical support to the development of Z23 low permeability reservoir.

\subsection{Numeric Simulation Scheme}

Different water injection parameters have varying degrees of impact on the well performance. The influence of water injection time and injection rate on North Z23 oil field performance have been discussed in this paper at a given five-spot water injection pattern. The studying range of injection time are advanced water injection 12 months, advanced water injection 9 months, advanced water injection 6 months, advanced water injection 3 months, synchronous water injection, oil well to injection after production 3 months, oil well to injection after production 6 months, oil well to injection after production 9 months, oil well to injection after production 12 months, oil well to injection after production 18 months, oil well to injection after production 24 months. The studying ranges of injection rate are $8 \mathrm{~m}^{3} /$ day, $11 \mathrm{~m}^{3} / \mathrm{day}, 14 \mathrm{~m}^{3} /$ day, $17 \mathrm{~m}^{3} /$ day and $20 \mathrm{~m}^{3} /$ day. Set block oil recovery, total oil production and water cut as targets to optimize water injection parameters.

\subsection{Numeric Simulation Procedures}

\section{(1) Optimization of water injection time}

Before the optimization of injection time, some related parameters should be assured. According to the character of water injection for low permeability reservoir, the water injection rate is set as $14 \mathrm{~m}^{3}$ per day, water injection pressure is set as $20 \mathrm{MPa}$, production pressure for production wells is set as $20 \mathrm{MPa}$, the initial daily production rate is set as $15 \mathrm{~m}^{3} /$ day, the simulation time is set as ten years.

Comparative analysis of block oil saturation, recovery, oil production rate, total oil production, formation pressure and water cut under different injection time are carried out in the following text.

\section{(2) Optimization of water injection rate}

Before the optimization of injection rate, some related parameters should be determined. The water injection time is set According to the above optimization results, water injection pressure is set as $20 \mathrm{MPa}$, production pressure for production wells is set as $20 \mathrm{MPa}$, the initial daily production rate is set as $15 \mathrm{~m}^{3} /$ day, the simulation time is set as ten years. The changes of oil saturation, block recovery, daily oil production rate, total oil production, formation pressure and water cut at the injection rate ranging from $8 \mathrm{~m}^{3} /$ day, $11 \mathrm{~m}^{3} /$ day, $14 \mathrm{~m}^{3} /$ day, $17 \mathrm{~m}^{3} /$ day to $20 \mathrm{~m}^{3} /$ day are analyzed.

\section{Result Analysis and Discussion}

\subsection{Optimization of Water Injection Time}

\subsubsection{Impact of Different Injection Time on Block Dynamic Performance:}

(1) Impact on block oil saturation 


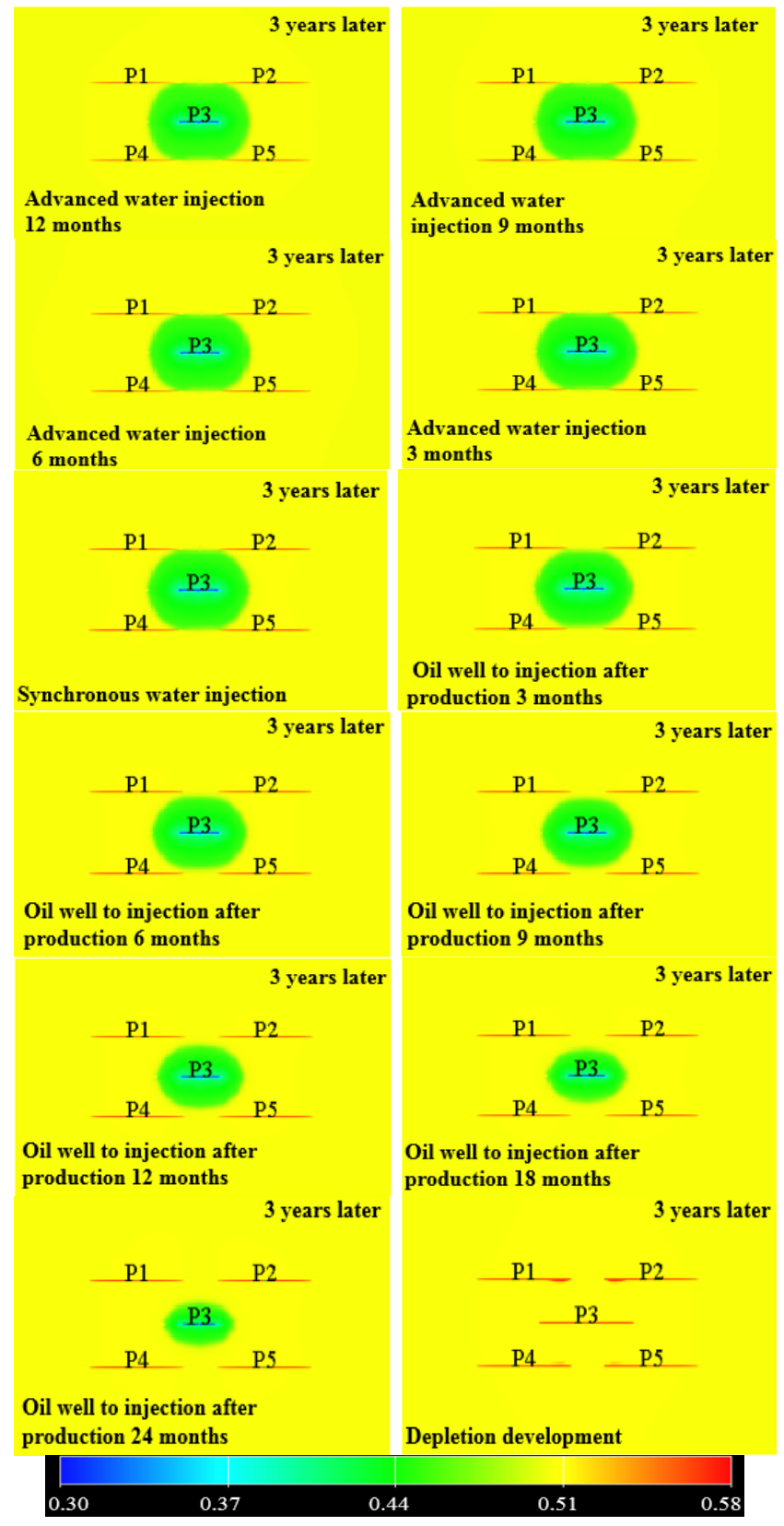

Figure 1. Changes of Block Oil Saturation under Different Injection Time

Figure 1shows that duo to the hydrophilic reservoirs and weak water sensitivity, water injection method contributes to a high block oil driving efficiency compared with depletion. Meanwhile, the fluid water sweep efficiency increase with the increasing of advanced injection time. The later oil well to injection the more serious formation pressure deficit. Although the oil well to injection after production method can increase formation pressure to some degree, the amount of increase is rather weak.

(2) Impact on block oil recovery

In Figure 2 the block oil recovery under different injection time is analyzed. It obvious that the increasing rate of block oil recovery in first two years is higher than that of two years later. During the initial production time, the block oil recovery of advanced water injection and synchronous water injection are less than that of oil well to injection and depletion as there are only 4 oil wells in production for the former, 
while 5 wells for later. After 8 years of production, the minimum block oil recovery is depletion method with $9 \%$, while the maximum is the water injection method with $12.92 \%$ under advanced water injection 12 months.

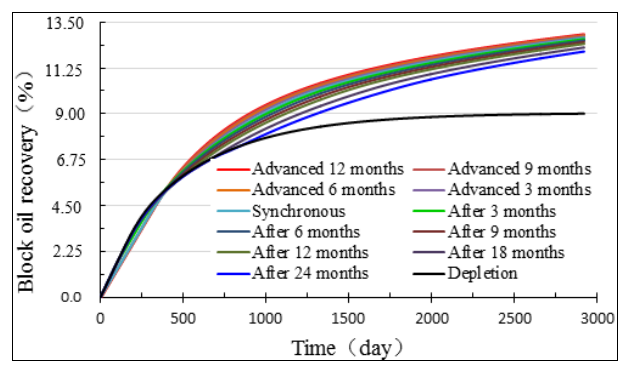

Figure 2. Impact of Injection Time on Block Oil Recovery

(3) Impact on block oil production rate

The oil production rate under different injection time plot in Figure 3 shows the initial production rate of single well can maintain at $15 \mathrm{~m}^{3} /$ day for a certain period, but falls down gradually with time. In the advanced injection time, the block oil production rate of water injection development is less than that of depletion as there are only 4 oil wells in production while 5 wells for depletion. In the later production process, production rate of depletion has a rapidly decrease while the injection method maintain a higher level as the formation pressure supplement from injection water. The depletion method has a rapid decrease of production rate, the oil well to injection method has a recovery in production rate and the advanced water injection method has longest stable production rate. After 8 years of production, the minimum block oil production rate is depletion method with $0.33 \mathrm{~m}^{3}$ per day, while the maximum is the oil well to injection method with $5.42 \mathrm{~m}^{3}$ per day at the injection time of oil well to injection after production 24 months.

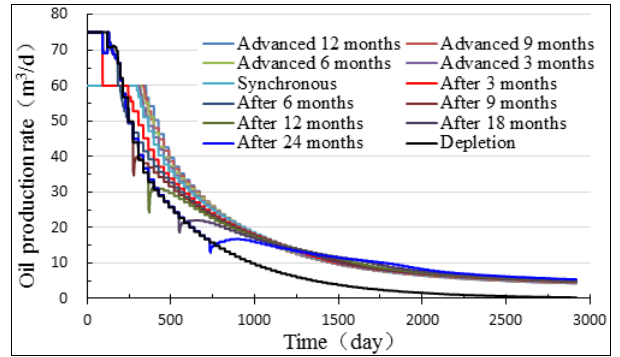

Figure 3. Impact of Injection Time on Block Oil Production Rate

(4) Impact on block total oil production

Figure 4 shows the changes of block total oil production increases with injection time. At the same time, the block total oil production increasing rate of first two years is higher than that of two years later. After 5 years of production, the minimum block total oil production is depletion method with $3.86 \times 10^{4} \mathrm{~m}^{3}$, while the maximum is $5.08 \times 10^{4} \mathrm{~m}^{3}$ at the injection time of advanced water injection 12 months. 


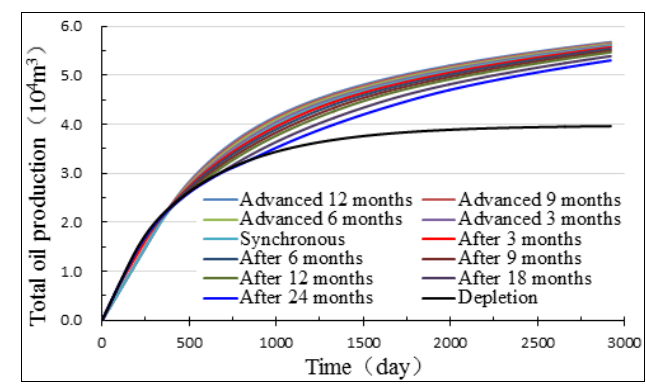

Figure 4. Impact of Injection Time on Block Total Oil Production

(5) Impact on block water cut

Shown in Figure 5 is the influence of water injection time on block water cut. Water injection development contributes to water breakthrough time to some extent, the earlier advanced water injection time the earlier water breakthrough time. Block water cut increases from $44.5 \%$ to $70.07 \%$ under water different water injection time, while the depletion maintains a level around $43 \%$.

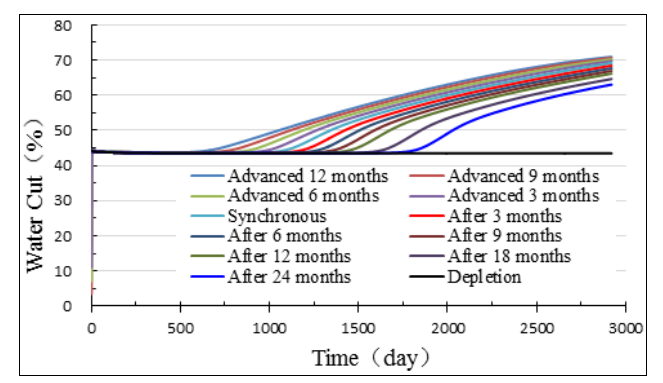

Figure 5. Impact of Injection Time on Block Water Cut

4.1.2. Optimization of Water Injection Time: According to the above simulation results, some curves have been plotted to optimize the water injection time.

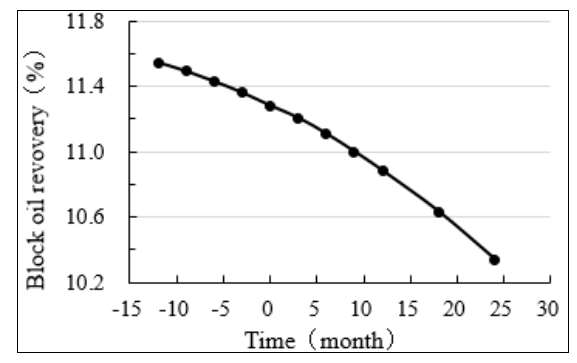

(a)

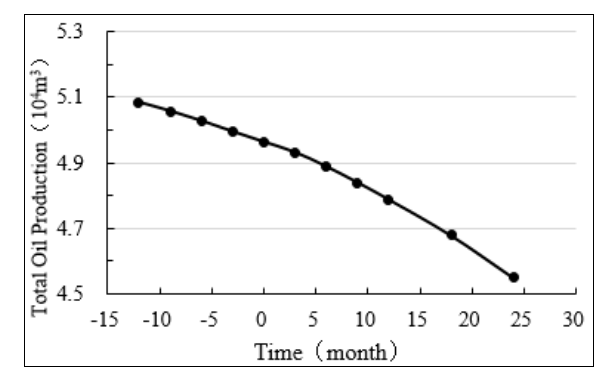

(b) 


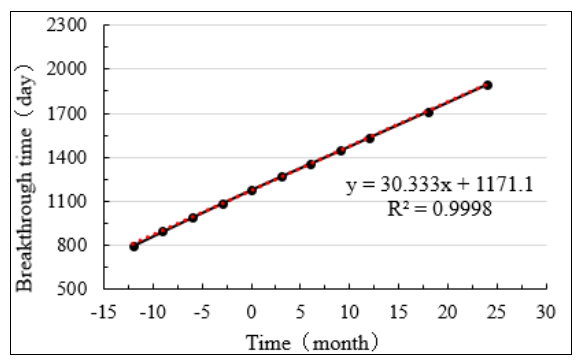

(c)

\section{Figure 6. Influence of Water Injection Time on Block. (a) Block Recovery, (b) Block Total Oil Production after Production 5 years, (c) Water Breakthrough Time}

Injection time less than 0 means advanced water injection method, equal to 0 means synchronous water injection method, more than 0 means oil well to injection after production a time. As shown in Figure 6 (a), the advanced water injection method has highest block recovery. After 5 years of production, the block recovery has increased $0.40 \%$ under the injection time from oil well to injection after production 12 months to synchronous water injection, while that of $0.26 \%$ from synchronous water injection to advanced water injection 12 moths.

Figure 6 (b) shows that the advanced water injection method has highest total oil production compared the others. After 5 years of production, the block total oil production has increased $0.18 \times 10^{4} \mathrm{~m}^{3}$ under the injection time from oil well to injection after production 12 months to synchronous water injection, while that of $0.12 \times 10^{4} \mathrm{~m}^{3}$ from synchronous water injection to advanced water injection 12 moths.

As shown in Figure 6 (c), the block water breakthrough time has a linear function relationship with water injection time. The advanced water injection way has an earlier water breakthrough time and the oil well to injection has a later water breakthrough time. The breakthrough time is about 789 days under the injection time of advanced water injection 12 months, while that of 1178 days under the injection time of synchronous water injection, 1896 days under the injection time of oil well to injection after production 24 months. In order to prevent the premature water breakthrough time, it should choose the suitable injection time.

The maximum formation pressure through water injection equals to hydrostatic pressure plus the water injection pressure. The formation pressure distribution before production under different advanced water injection time is showed in Figure 8. As the maximum formation pressure is $55 \mathrm{MPa}$ in this paper, after 3 months of advanced water injection, the formation pressure near injection well is 53.4MPa, while that of 6 months of advanced injection is $55 \mathrm{MPa}$ which is close to the limit pressure(Figure 8). So advanced water injection 6 months may cause a security risk.

Considering the well performance under production time and develop time, water breakthrough time and the security of injection devices, it can be concluded that the preferred water injection time is advanced water injection 3 months when the water breakthrough time is about 3 years. 


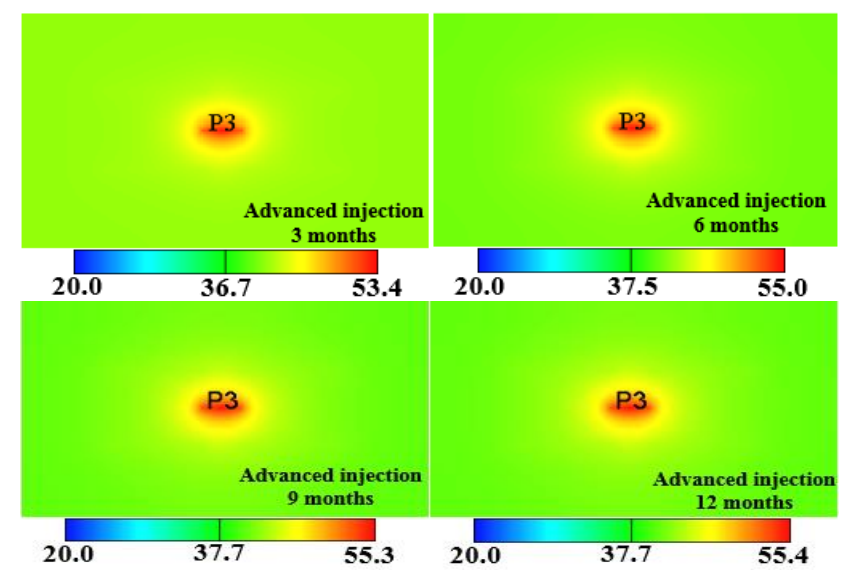

Figure 7. Formation Pressure Distribution before Production under Different Advanced Water Injection Time

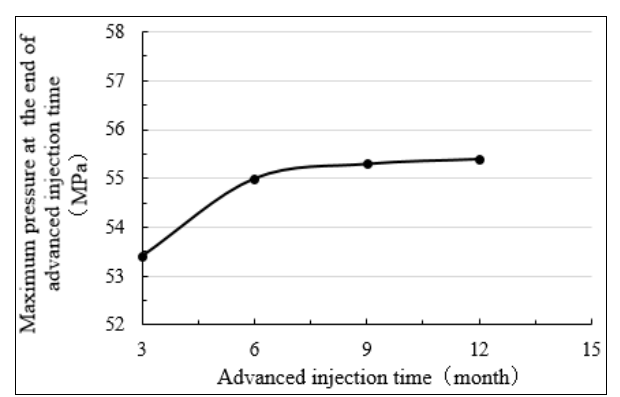

Figure 8. The Influence of Advanced Water Injection Time on Maxima Pressure near Injection Well Before Production

\subsection{Optimization of Water Injection Rate}

4.2.1. Impact of Different Injection Rate on Block Dynamic Performance:

(1) Impact on block oil saturation

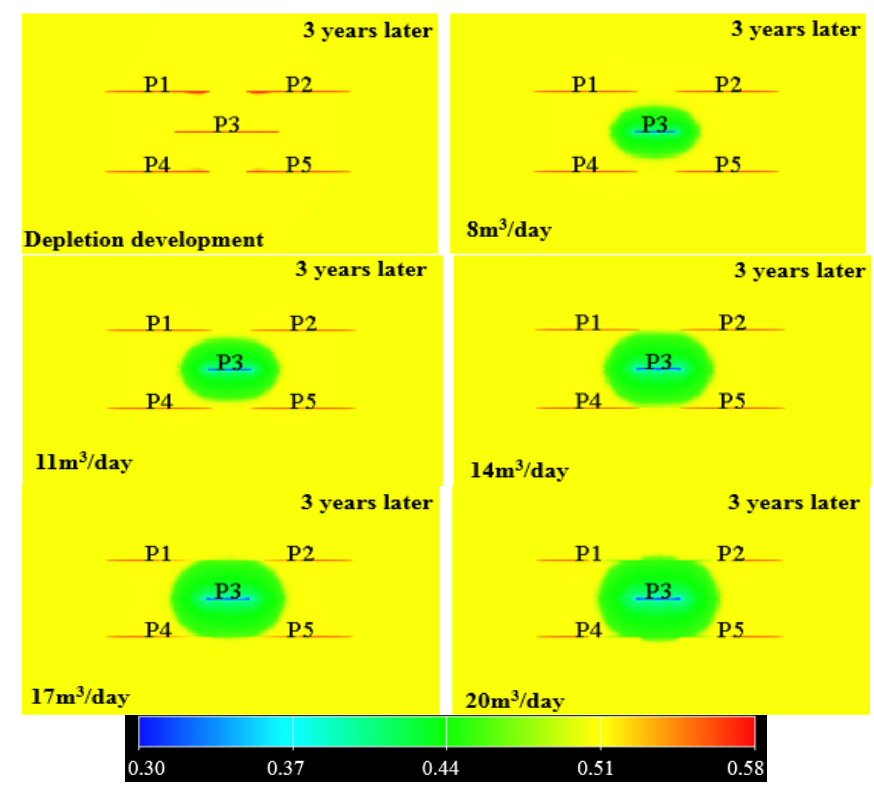

Figure 9. Changes of Block Oil Saturation under Different Injection Rate 
Figure 9 shows that compared with depletion, water injection method contributes to the Improvement of well group oil displacement efficiency. Meanwhile, with the increasing of injection rate, the fluid water sweep area has extended gradually which promote the recovery. After three years' production, part of the injection water has run into oil wells through the hydraulic fractures. On one hand, the injection water sweep efficiency has improved, on the other hand, the wells' water breakthrough time has shortened.

(2) Impact on block oil recovery

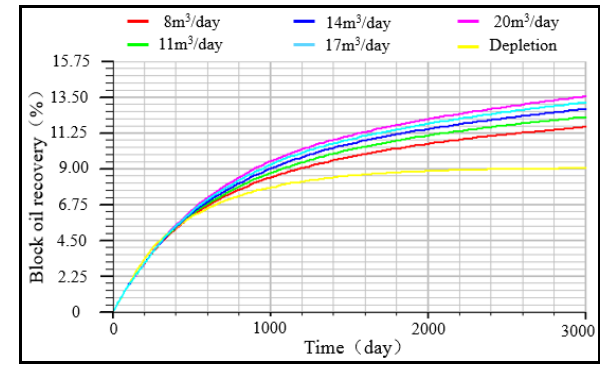

Figure 10. Impact of Injection Rate on Block Oil Recovery

In Figure 10 the block oil recovery under different injection rate is analyzed. The block oil recovery increases with the increasing of injection rate, at the same time, the recovery increasing rate of first two years is higher than that of two years later. After 8 years of production, the minimum block oil recovery is depletion method with $9 \%$, while the maximum is the water injection method with $13.46 \%$ at the injection rate $20 \mathrm{~m}^{3}$ per day.

(3) Impact on block oil production rate

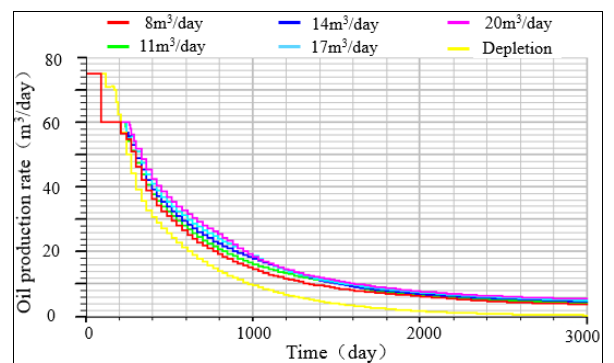

Figure 11. Impact of Injection Rate on Block Oil Production Rate

The oil production rate under different injection rate plot in Figure 8 (right) shows the initial production rate of single well can maintain at $15 \mathrm{~m}^{3} /$ day for a certain period. In the advanced injection time, the block oil production rate of water injection development is less than that of depletion as there are only 4 oil wells in production while 5 wells for depletion. In the later production process, production rate of depletion has a rapidly decrease while the injection method maintain a higher level as the formation pressure supplement from injection water. After 8 years of production, the minimum block oil production rate is depletion method with $0.33 \mathrm{~m}^{3}$ per day, $9 \%$, while the maximum is the water injection method with $5.38 \mathrm{~m}^{3}$ per day at the injection rate $20 \mathrm{~m}^{3}$ per day. 
(4) Impact on block total oil production

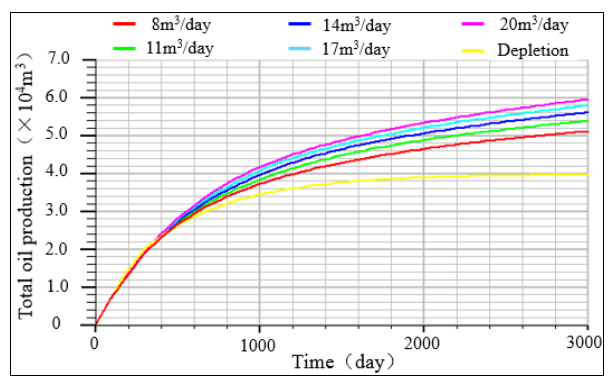

Figure 12. Impact of Injection Rate on Block Total Oil Production

Figure 12 shows that the block total oil production increases with the increasing of injection rate. At the same time, the block total oil production increasing rate of first two years is higher than that of two years later. After 8 years of production, the minimum block total oil production is depletion method with $3.96 \times 10^{4} \mathrm{~m}^{3}$, while the maximum is the water injection method with $5.92 \times 10^{4} \mathrm{~m}^{3}$ at the injection rate $20 \mathrm{~m}^{3}$ per day.

(5) Impact on block water cut

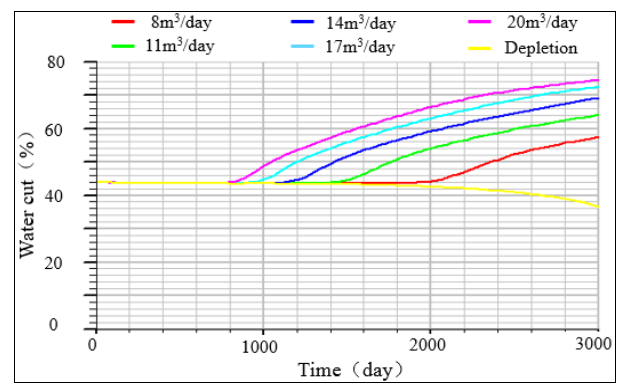

Figure 13. Impact of Injection Rate on Block Water Cut

Shown in Figure 13 is the influence of water injection rate on block water cut. Water injection development contributes to water breakthrough time to some extent, the higher water injection rate the earlier water breakthrough time. Block water cut increases from $44.5 \%$ to $74.07 \%$ under water injection development, while the depletion maintains a level around $40 \%$.

(6) Impact on block total water injection

The total water injection under different injection rate plot in Figure 14 shows that the total water injection increases with the water injection rate. After 8 years of production, the maximum block total water injection is the water injection method with $5.84 \times 10^{4} \mathrm{~m}^{3}$ at the injection rate $20 \mathrm{~m}^{3}$ per day. 


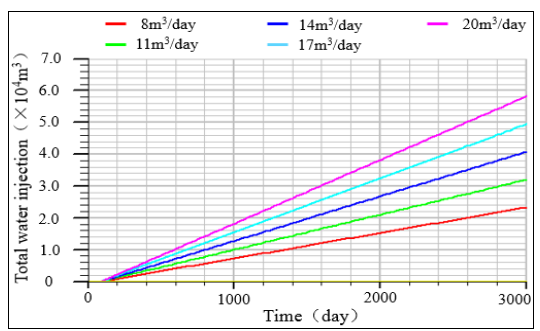

Figure 14. Impact of Injection Rate on Total Water Injection

\subsubsection{Optimization of water injection rate:}

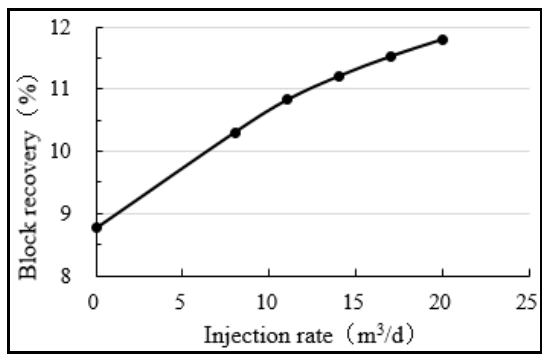

Figure 15. Impact of Injection Rate on Total Water Injection and Block Recovery after Production

As shown in Figure 15, the greater injection rate the higher block recovery. After 5 years of production, the block recovery has increased $0.9 \%$ under the injection rate from $8 \mathrm{~m}^{3} /$ day to $14 \mathrm{~m}^{3} /$ day, while that of $0.59 \%$ from $14 \mathrm{~m}^{3} /$ day to $20 \mathrm{~m}^{3} /$ day.

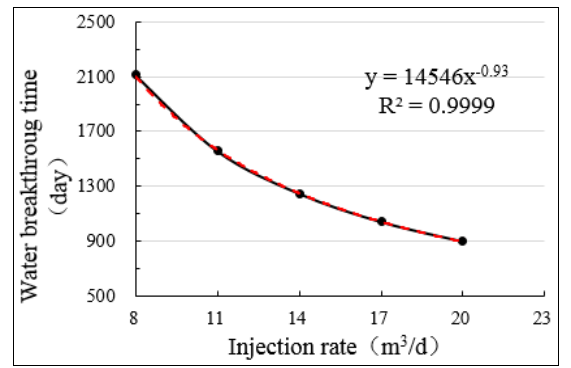

Figure 16. Influence of Water Injection Rate on Block Water Breakthrough Time

As shown in Figure 16, the block water breakthrough time has a power function relationship with water injection rate, the greater water injection rate the earlier water breakthrough time. The breakthrough time is about 2111days under the injection rate of $8 \mathrm{~m}^{3} /$ day, while that of 900 days under the injection rate of $20 \mathrm{~m}^{3} /$ day. In order to prevent the premature water breakthrough time, it should slow down the water injection rate. 


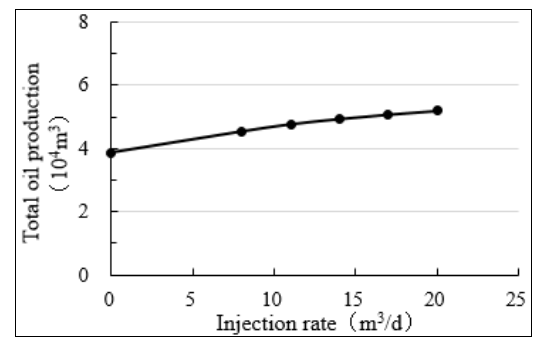

Figure 17. Influence of Water Injection Rate on Block Total Oil Production

As shown in Figure 17, the greater water injection rate the higher block total oil production. After 5 years of production, the block total oil production has increased $0.40 \times 10^{4} \mathrm{~m}^{3}$ under the injection rate from $8 \mathrm{~m}^{3} /$ day to $14 \mathrm{~m}^{3} /$ day, while that of $0.26 \times 10^{4} \mathrm{~m}^{3}$ from $14 \mathrm{~m}^{3} /$ day to $20 \mathrm{~m}^{3} /$ day.

Simulation results show that, the recovery and total oil production at five years increase with the increasing of water injection rate, but with a gradually slowing down increasing rate. Meanwhile the water breakthrough time has a power function with the injection rate. At the situation of high block oil recovery, try to ensure that the wells have a rather longer water breakthrough time to prevent the premature water flood. Although the block has a rather high recovery under high injection rate, the increase was not so obvious, the water breakthrough time was short and high injection rate means high cost.

From the above analysis, it can be concluded that the preferred water injection rate is $14 \mathrm{~m}^{3} /$ day with a water breakthrough time 1248 days. Simulation results show that the block recovery is $11.21 \%$ and the block total oil production is $4.93 \times 10^{4} \mathrm{~m}^{3}$ after five years' production.

\section{Conclusion}

To figure out the optimal injection parameters for water well in tight sand reservoir, a five spot well pattern was applied to model the production performance of block. In this preliminary work different injection parameters of water wells were considered. The block oil saturation, block oil recovery, total oil production, water cut and block water breakthrough time were then calculated and analyzed. Simulation results show that water injection method contributes to a high block oil driving efficiency compared with natural, also, the fluid water sweep efficiency increase with the increasing of advanced injection time. It was observed that the block water breakthrough time has a linear function relationship with water injection time, so, advanced water injection way tend to contribute an earlier water breakthrough time. Considering the well performance under production time, water breakthrough time and the security of injection devices, advanced water injection 3 months was determined as the optimal injection time with water breakthrough time 3 years around. Then, the optimal injection rate was discussed.

High injection rate contributed to large fluid water sweep area which promote the block oil recovery, however, the higher water injection rate the earlier water breakthrough time. Although the block has a rather high recovery under high injection rate, the increase was not so obvious, the water breakthrough time was short and high injection rate means high cost. From the above analysis, it can be concluded that the preferred water injection rate is $14 \mathrm{~m}^{3} /$ day with a water breakthrough time 1248 days. 


\section{Acknowledgement}

The authors would like to thank the National Natural Science Foundation of China (51374178) and National Science and Technology Major Project of China (2011ZX05002-004-007HZ) for their financial support. Also, the authors would like to thank SINOPEC Inc. for providing the reservoir data.

\section{References}

[1] Denney D., "Characterization of water injection in low-permeability rock using sandstone micromodels [J]", Journal of Petroleum Technology, vol. 56, no. 5, (2004), pp. 71-72.

[2] Abass E. and Fahmi A., "Experimental Investigation of Low Salinity Hot Water Injection to Enhance the Recovery of Heavy Oil Reservoirs[C]", North Africa Technical Conference and Exhibition, SPE, 164768, (2013).

[3] Sun W. and Tang G. Q., "Visual study of water injection in low permeable sandstone [J]", Journal of Canadian Petroleum Technology, vol. 45, no. 11, (2006).

[4] Sadeghi M., Movahedinia A. and Fath A. H., "Investigation of immiscible CO2 and C1 injection and comparison with water injection for enhanced oil recovery in naturally fractured reservoirs[J]", Petroleum Science and Technology, vol. 34, no. 3, (2016), pp. 232-239.

[5] Valk P., "Economides M J. Hydraulic fracture mechanics [M]", Wiley, New York, (1995).

[6] Nasralla R. A and Nasr-El-Din H. A., "Double-layer expansion: is it a primary mechanism of improved oil recovery by low-salinity water flooding? [J]", SPE Reservoir Evaluation \& Engineering, vol. 17, no. 1, (2014), pp. 49-59.

[7] Sohrabi M., Mahzari P. and Farzaneh S. A., "Novel insights into mechanisms of oil recovery by low salinity water injection [C]", SPE, 172778, (2015).

[8] Nasralla R A, Bataweel M. A. and Nasr-El-Din H. A., "Investigation of wettability alteration and oilrecovery improvement by low-salinity water in sandstone rock [J]", Journal of Canadian Petroleum Technology, vol. 52, no. 2, (2013), pp. 144-154.

[9] Espinola O., Mehranfar R. and Salama D., "Defining the Optimum Exploitation Strategy Combining Water Injection, Field Development and Artificial Lift Analysis to a Mature Field through Surface and Sub-surface Coupled Models [C]”, SPE, 177204, (2013).

[10] Xinquan R., "Theory and practice of advanced water injection [M]", Beijing: Petroleum Industry Press, (2011), pp. 26-36.

[11] Hadi S., Alawiyah S. and Gunawan W., "Integration of 4D Microgravity, Geology and Production Data to Monitor Water Injection in Improved Oil Recovery Project", Diamond Field[C] IPTC, 17101, (2013)

[12] Mendez A. J., Chacin B. and Balram S., "Successful Application of Water Injection to Increase Oil Recovery in Boscán Field [C]”, SPE, 169412, (2014).

[13] Patzek T. W. and Silin D. B., "Fluid injection into a low-permeability rock-1 Hydrofrature growth [C]", SPE, 39698, (1998).

[14] Ovens J., Larsen F. P. and Cowie D. R., "Making sense of water injection fractures in the Dan field [J]”, SPE Reservoir Evaluation \& Engineering, vol. 1, no. 6, (1998), pp. 556-566.

[15] Hua Y. and Jinhua F., "Exploration theory and technology of ultra-low permeability reservoirs [M]", Beijing: Petroleum Industry Press, (2007), pp. 66-69.

[16] Chunxia Q., Qiulian Y. and Dengfei L., "Influencing factors of low permeability reservoir property of Yanchang formation in Changqing Oilfield [J]", Lithologic Reservoirs, vol. 2, no. 20, (2008), pp. 43-47.

[17] Wei Z., "Study on optimization design method of horizontal well pattern with low permeability [M]", Daqing: Daqing Petroleum Institute, (2009), pp. 34-55.

[18] Liming L., Hanqiao J. and Jialing N., "Research on multi-objective optimization method of horizontal injection-production patterns [J]", Petroleum Geology and Recovery, vol. 1, no. 19, (2012), pp. 85-90.

[19] Qian G., Jiang X. and Zhang H., "Numerical Simulation Study of Water Injection Development in an Extra-low-permeability Fractured Reservoir, Xiaoguai Oilfield [C]", Society of Petroleum Engineers, (2000).

[20] Siagian T., Baroek M. and Fitri N., "The Evaluation of Water Injection Impact in a Fractured Basement Gas Reservoir by Using Mechanistic Modelling Approach [C]”, International Petroleum Association 39th Annual Conventional \& Exhibition, (2015). 
International Journal of Smart Home

Vol. 11, No. 1 (2017) 